University of Nebraska - Lincoln

DigitalCommons@University of Nebraska - Lincoln

Sociology Department, Faculty Publications

Sociology, Department of

2011

\title{
Pregnancy and Mental Health of Young Homeless Women
}

\author{
Devan M. Crawford \\ University of Nebraska-Lincoln, dcrawford3@unl.edu \\ Emily C. Trotter \\ University of Nebraska-Lincoln, emilyhaferbier@hotmail.com \\ Kelley J. Sittner Hartshorn \\ University of Nebraska-Lincoln, kelley.sittner@okstate.edu \\ Les B. Whitbeck \\ University of Nebraska-Lincoln, Iwhitbeck2@unl.edu
}

Follow this and additional works at: https://digitalcommons.unl.edu/sociologyfacpub

Part of the Family, Life Course, and Society Commons, and the Social Psychology and Interaction Commons

Crawford, Devan M.; Trotter, Emily C.; Sittner Hartshorn, Kelley J.; and Whitbeck, Les B., "Pregnancy and Mental Health of Young Homeless Women" (2011). Sociology Department, Faculty Publications. 298. https://digitalcommons.unl.edu/sociologyfacpub/298

This Article is brought to you for free and open access by the Sociology, Department of at DigitalCommons@University of Nebraska - Lincoln. It has been accepted for inclusion in Sociology Department, Faculty Publications by an authorized administrator of DigitalCommons@University of Nebraska - Lincoln. 
Published in final edited form as:

Am J Orthopsychiatry. 2011 April ; 81(2): 173-183. doi:10.1111/j.1939-0025.2011.01086.x. Copyright 2011 APA.

\title{
Pregnancy and Mental Health of Young Homeless Women
}

\author{
Devan M. Crawford, \\ Department of Sociology, University of Nebraska-Lincoln, 206 Benton Hall, Lincoln NE \\ 68588-0623, (402) 472-2243, dcrawfrd@unlserve.unl.edu
}

Emily C. Trotter,

Department of Sociology, University of Nebraska-Lincoln, 209 Benton Hall, Lincoln NE 68588-0623, (402) 472-3632, emilyhaferbier@hotmail.com

Kelley J. Sittner Hartshorn, and

Department of Sociology, University of Nebraska-Lincoln, 209 Benton Hall, Lincoln NE 68588-0623, (402) 472-3632, kelley.hartshorn@gmail.com

\section{Les B. Whitbeck}

Department of Sociology, University of Nebraska-Lincoln, 739 Oldfather Hall, Lincoln, NE 68588-0324, (402) 472-5562, Iwhitbeck2@unl.edu

\begin{abstract}
Pregnancy rates among women in the U.S. who are homeless are much higher than rates among women who are housed (Greene \& Ringwalt, 1998). Yet little research has addressed mental health, risk and resilience among young mothers who are homeless. This study utilizes a sample of women from the Midwest Longitudinal Study of Homeless Adolescents (MLSHA) to investigate pregnancy and motherhood over three years among unaccompanied homeless young mothers. Our data are supplemented by in-depth interviews with a subset of these women. Results show that almost half of sexually active young women $(n=222, \mu$ age $=17.2)$ had been pregnant at baseline (46.4\%), and among the longitudinal subsample of 171 women ( $\mu$ age $=17.2$ ), almost $70.0 \%$ had been pregnant by the end of the study. Among young mothers who are homeless, only half reported that they helped to care for their children consistently over time, and one-fifth of the women reported never seeing their children. Of the young women with children in their care at the last interview of the study (Wave 13), almost one-third met criteria for lifetime major depressive episode (MDE), lifetime posttraumatic stress disorder (PTSD), and lifetime drug abuse, and onehalf met criteria for lifetime antisocial personality disorder (APD). Twelve-month diagnoses are also reported. The impacts of homelessness on maternal and child outcomes are discussed, including the implications for practice, policy, and research.
\end{abstract}

\section{Keywords}

pregnancy; motherhood; health; mental health; homeless; runaway adolescents

\section{Pregnancy and Mental Health of Young Homeless Women}

Although rates of homelessness among young people are difficult to assess because the population is often hidden and transient (Ringwalt, Greene, Robertson, \& McPheeters, 1998), statistics from the Office of Juvenile Justice and Delinquency Prevention indicate that there were approximately 1.6 million homeless runaway and thrownaway youth under 18

*Address correspondence to Devan Crawford, Department of Sociology, 206 Benton Hall, University of Nebraska-Lincoln, Lincoln, NE 68588-0623; dcrawfrd@unlserve.unl.edu. 
years of age in 1999 (Hammer, Finkelhor, \& Sedlak, 2002). Of particular concern is the number of young women who become pregnant while homeless. This number has been steadily growing over the last 30 years. Recent estimates show that between $6 \%$ and $22 \%$ of young homeless females may be pregnant (Health Resources and Services Administration, 2001), whereas pregnancy rates in the general population (aged 18-19) are just above twelve percent (Guttmacher Institute, 2006).

The physical and mental stresses of pregnancy and the pressures of caring for young children can complicate the process of extricating oneself from homelessness (Webb, Culhane, Metraux, Robbins, \& Culhane, 2003). Mental health problems are prevalent among homeless mothers (Bassuk, Buckner, Perloff, \& Bassuk, 1998), and are exacerbated by time spent living on the street (Cauce et al., 2000). Moreover, homelessness during pregnancy increases risks for birth complications, low birth weight, and nutritional or substance abuse related physical and neurological effects on newborns (Chapman, Tarter, Kirisci, \& Cornelius, 2007; Little et al., 2005; Stanwood \& Levitt 2004; Stein, Lu, \& Gelberg, 2000).

This study is based on a sample of young women who were homeless (aged 16-19 at baseline) and who participated in a three-year longitudinal study that followed homeless adolescents as they moved from late adolescence into early adulthood. The findings are informed by in-depth interviews with a subsample of these women. We investigated pregnancy, mental health, and motherhood at baseline and across the three years of the study.

\section{Pregnancy and Health Risks among Young Homeless Women}

Approximately $1 \%$ of the homeless population is comprised of unaccompanied young people who have left home (U.S. Conference of Mayors, 2007), due to family problems, economic disadvantage, or residential instability (Duffield, 2001). Homeless episodes interrupt typical adolescent development and the transition to adulthood by disrupting education and substituting exposure to conventional peers and adult caretakers for largely nonconventional support groups (Hagan \& McCarthy, 1997; Markos \& Lima, 2003; Powers \& Jaklitsch, 1993; Whitbeck \& Hoyt, 1999). The need to make their own way often draws homeless young people into the street economy, increasing risk for victimization and the likelihood of involvement in the criminal justice system (Hagan \& McCarthy, 1997; Whitbeck \& Hoyt, 1999; Whitbeck, 2009). There is abundant evidence that homeless young people are highly sexually active and often engage in unprotected sex, resulting in high rates of sexually transmitted infections (Noell, Rohde, Seeley, \& Ochs, 2001). Furthermore, homeless young women have high rates of pregnancy and early parenthood (Greene \& Ringwalt, 1998; Haley et al., 2004). Pregnancy and early parenthood among young homeless women is a leading cause of under education and lost opportunities for successful adult adjustment (Nunez \& Fox, 1999).

Most women who are homeless have been pregnant at some point in their lives. Recent pregnancy statistics from Minneapolis show that among homeless youth aged 15-22 years, over half of the young women had been pregnant at least once (Halćon \& Lifson, 2004). Furthermore, youth who are homeless may be at increased risk for multiple pregnancies. Halćon \& Lifson (2004) reported almost 30\% of the young women in their sample had been pregnant two or more times. Becker and colleagues (1992) reported that half of all women in a New York City homeless sample had experienced pregnancy four or more times (cited in Bassuk \& Weinreb, 1993).

These statistics are not surprising when one looks at contraception use among homeless young people. In a recent study by Arangua and colleagues (2005), $42 \%$ of sexually active (fertile) women who were homeless did not use any form of birth control when engaging in 
vaginal sex in the past 12 months. Of the women who were homeless who used contraception, condoms were the most frequently used (Arangua, Andersen, \& Gelberg, 2005; Gelberg, Lu, Leake, Andersen, Morgenstern, \& Nyamathi, 2008), yet only one-third of homeless women said they consistently used condoms when having vaginal intercourse (Gelberg et al., 2008). This is especially problematic among those who are monogamous. Women in stable relationship were two times more likely to forgo contraceptive use than those women with multiple partners (Gelberg et al., 2008) putting them at increased risk for unintended pregnancy.

Homelessness may have serious negative consequences for the health of pregnant women regardless of age at which they become pregnant. However, these effects may be more pronounced among younger women. Adolescent pregnancies tend to be difficult physically and emotionally even among young women who are housed and have intact support systems. Bassuk and Weinreb (1993) point out that homeless women who become pregnant are usually young and there is evidence that they are likely to suffer from acute and chronic health problems (Wagner \& Menke, 1992; Weinreb, Goldberg, \& Perloff, 1998), and often report poor nutritional intake (Oliveira \& Goldberg, 2002). Regardless of age, mothers who are homeless report depression and stress (Meadows-Oliver, 2002; Tischler, Rademeyer, \& Vostanis, 2007) as well as post-traumatic stress disorder and comorbid mental disorders (Bassuk et al., 1998). Women who are homeless also report high rates of alcohol consumption while pregnant. Wagner and Menke (1992) estimated that thirty-eight percent of women in their sample who were homeless drank alcohol while pregnant. Substance abuse may further reduce already low rates of prenatal care among this population in that women who use substances are less likely than those who do not use substances to receive prenatal care when pregnant (Stein, Lu, \& Gelberg, 2000). Alcohol use while pregnant also is associated with alcohol related neurological effects among offspring, including fetal alcohol spectral disorders (Chapman et al., 2007; Stanwood \& Levitt, 2004), and substance use increases the risk of miscarriage. Recent estimates put the rate of miscarriage among women who are homeless at between 35 and 70 percent depending on samples (Gelberg et al., 1999; Halćon \& Lifson, 2004).

Many mothers who are homeless end up relinquishing their children either voluntarily or involuntarily to family members or to the child welfare system. This is particularly true of younger women who have may have fewer resources to draw upon. Although the results are not broken down by age of mother, a recent five-year study of child welfare involvement and foster care placement indicated that $37 \%$ of children with mothers experiencing homelessness were involved with the child welfare system (Culhane, et al., 2003). Among homeless families in New York City, 35\% had open child welfare supervision (Nunez, 1994). According to a survey of 195 children in foster care, approximately one-half of their birth parents had been homeless at some point (Zlotnick, Kronstradt, \& Klee, 1999).

\section{Life Histories and Learning to Parent}

Much of what we know about being a parent comes from the ways we have been parented. There is plentiful evidence that homeless young people leave or drift out of disorganized and often abusive families (Janus, Archambault, Brown, \& Welsh, 1995; Kaufman \& Widom, 1999; Kennedy, 1991; Kurtz, Kurtz, \& Jarvis, 1991; Molnar, Shade, Kral, Booth, \& Watters, 1998; Mounier \& Andujo, 2003; Noell, et al., 2001; Pennbridge, Yates, David, \& MacKenzie, 1990; Rotheram-Borus, Mahler, Koopman, Langabeer, 1996; Ryan, Kilmer, Cauce, Watanabe, Hoyt, 2000; Sullivan \& Knutson, 2000; Tyler, Hoyt, Whitbeck, \& Cauce, 2001; Tyler, Whitbeck, Hoyt, \& Cauce, 2004; Whitbeck \& Hoyt, 1999; Whitbeck \& Simons, 1993). Patterson and colleagues argue that such families are "basic training" for antisocial behaviors (Patterson, Dishion, \& Bank, 1984). Coercive/aggressive communication patterns learned in dysfunctional families are carried into to new situations 
such as school and peer groups where they elicit coercive/aggressive responses from teachers and peers. The results are academic problems, rejection by conventional peers, and drift into nonconventional peer groups that tolerate and reciprocate this style of interaction. If dysfunctional families are basic training for antisocial behaviors, certainly homeless episodes provide advanced training. There are few opportunities to learn conventional interactive skills and great pressure to learn survival skills for protection and to make one's way economically. Moreover, dysfunctional families and street experiences take an emotional toll.

Many young people who are homeless meet criteria for mental and substance abuse disorders or related symptoms. Couple this with the higher risk of low birth weight babies of difficult temperament, unstable housing, poverty, and few sources of social support, and you have young parents who are poorly prepared for the stresses of parenthood. It is difficult for any adolescent to become a parent but the risk for young people who are homeless is amplified by history and their current situation. Rutter and colleagues have shown that young women from abusive family backgrounds can learn to be good parents. However, they must specifically reject negative family experiences and choose another way to bring up their children. This involves conscious learning of new parenting skills (Rutter, Quinton, $\&$ Hill, 1990). Many young women who become pregnant while homeless will lack the necessary support and opportunities to learn these important skills.

\section{Summary}

Recent estimates indicate that twenty-three percent of the homeless population is composed of families with children (U.S. Conference of Mayors, 2007) and that most homeless families are headed by young women (Rog \& Buckner, 2007 as cited in National Coalition for the Homeless, 2008b). Women who experience homelessness often have increased rates of pregnancy and few life chances. A shortage of affordable housing, an increase in poverty, and substantial changes in welfare policies have put many single female headed families one financial emergency away from homelessness (Center on Budget and Policy Priorities, 2004; National Coalition for the Homeless, 2008a; 2008b).

We know very little about young women who are homeless who become pregnant or what happens to their children. We are aware of no prospective studies that have followed them through their pregnancies and beyond. Also, we have found no research that provides diagnostic information regarding the mental health and substance use of pregnant women who are homeless. In this study we will report on the pregnancy outcomes of young women who experience homelessness and provide the results of screenings for mental health and substance use diagnoses at the times the women were pregnant.

\section{Methods}

The data used for this report are from the Midwest Longitudinal Study of Homeless Adolescents (MLSHA), a 13-wave (3-year) study of adolescent youth who have experienced homelessness in four Midwestern states. To be eligible to participate, the young person had to be between the ages of 16 and 19 years old and homeless at the time of the baseline interviews. Our definition of "homeless" was that the adolescent had to reside in a shelter, on the street, or be living independently (e.g., friends, transitional living) because they had run away, been pushed out, or drifted out of their family of origin. Based on interviewer reports, approximately $90 \%$ of the 505 homeless and runaway adolescents who were approached for an initial interview and who met study criteria agreed to participate in the study. Of the 455 respondents who completed the first baseline interview, $94.3 \%$ or 428 (187 males and 241 females) completed the second baseline diagnostic interview within the next two weeks. Twenty-six of the 455 original respondents did not complete the diagnostic 
interview. Those who did not complete the interview had a significantly higher age at first run away (14.84 years vs. 13.41 years). They were more likely to report that they were heterosexual (100\% vs. $85 \%$ of completers) and less likely to report having been physically victimized when on their own than were individuals who completed more than one interview.

The respondents were interviewed by full time, specially trained interviewers directly on the streets and in shelters in eight Midwestern cities (St. Louis, Kansas City, Omaha, Lincoln, Des Moines, Cedar Rapids, Iowa City, and Wichita). The adolescents ranged in age from 16 to 19 years with an average age of 17.4 years $(\mathrm{SD}=1.05)$. Fifty-nine percent were European American, 22\% were non-Hispanic African American, 5\% were Hispanic, with the remaining self-identified as American Indian, Asian or Pacific Islander, or biracial. Fifteen percent identified themselves as gay, lesbian, or bisexual. Sixty-two percent of the adolescents reported that the population of their city of origin was 100,000 or greater, $10 \%$ said they were from a suburb of a large city, $8 \%$ were from a medium sized city $(50,000$ to $100,000), 8 \%$ were from a small city $(10,000$ to 50,000$)$, and $12 \%$ were from small towns or rural communities of 10,000 or less.

The adolescents were informed that this was a longitudinal study and the tracking protocols were explained. Informed consent was a two-stage process. First, the study was explained, and informed consent was obtained from the adolescent. They were assured that refusal to participate in the study, refusal of any question, or stopping the interview process at any time would have no effect on current or future services provided by the outreach agency in which the interviewer was placed. Second, all adolescents were asked if we could contact their parents. If permission was granted, parents were contacted, and informed consent to talk to a minor less than 18 years was verbally obtained. The parents were also asked to participate in a computer assisted telephone interview. Results from the parent interviews are not discussed in this study. If the adolescent was sheltered, we followed shelter policies of parental permission for placement and guidelines concerning granting such permissions. These policies were always based on state laws. In the few cases where the adolescent was under 18 years, not sheltered, and refused permission to contact parents, the adolescents were treated as emancipated minors in accordance with National Institute of Health guidelines (National Institute of Health, 2005). The consent process and questionnaires were approved by the University of Nebraska-Lincoln Institutional Review Board (\#2001-07-333 FB). A National Institute of Mental Health Certificate of Confidentiality was obtained to protect the respondent's statements regarding potentially illegal activities (e.g., drug use).

The street interviewers underwent two weeks of intensive training regarding computer assisted personal interviewing (CAPI) procedures and administering the four University of Michigan Composite International Diagnostic Interview (UMCIDI) indices (major depressive episodes, post-traumatic stress disorder, alcohol use/abuse, and drug use/abuse) and one Diagnostic Interview Schedule for Children-Revised (DISC-R) (conduct disorder) index. They then returned to their shelters and administered several "practice" interviews with staff and respondents 20 years or older. After completing their practice interviews, the interviewers returned to the university for a second week of training. All interviews were conducted on laptop computers and downloaded electronically to a special secure university server.

We designed a sampling strategy for the current study that incorporated sampling units of fixed and natural sites similar to the design Kipke used in her Los Angeles study of homeless youths (Kipke, O'Connor, Nelson, \& Anderson, 2000) with a year long window of sampling to capture the time dimensions. This sampling design involved repeatedly checking locations where homeless youths were likely to be found in each of the target 
cities. Locations included shelters and outreach programs serving homeless youths, drop-in centers, and various street locations where young homeless people were most likely to be located. Research has demonstrated that using sampling designs that involve multiple points of entry to homeless populations are most effective in generating a diverse sample (Burt, 1996a; 1996b; Koegel, Burnam, \& Morton, 1996). The interviewers all had prior experience in their respective cities as youth outreach workers and brought considerable knowledge regarding optimal areas of the city for locating youths on their own. The sampling protocol included going to these locations in the cities at varying times of the day on both weekdays and weekends over the course of 12 months.

Because episodes of homelessness are of varying duration, a one-year time frame provided an increased probability of capturing youths who have short-term exposure to homelessness. The interviewers were instructed to continue recruiting until their caseload reached 60 adolescents who they would then track and re-interview at three-month intervals. The baseline interview consisted of social history and symptom scales. In addition, the respondent was then asked to meet for a second interview during which the diagnostic interviews were conducted. These two interviews made up the baseline assessment for the study and usually were completed within one or two days so that no significant time lapsed between the first part of the baseline interview and the second diagnostic interview. The respondents were paid $\$ 25$ for each interview. It is important to note that even with our detailed sampling design; our sample is not random and is not representative of all homeless youth.

The qualitative data used throughout this paper were supported by a University of NebraskaLincoln Faculty Seed Grant. These funds supported semi-structured interviews with a subsample of 40 (16 males and 24 females) MLSHA subjects. Project interviewers conducted the interviews which were audio taped and transcribed by project workers. All identifying information was removed from the transcript files and demographic information was tracked using subject identification numbers. The interviews lasted on average, about one hour. Transcripts were thematically coded by authors, focusing on any discussion of pregnancy, birth, babies, children, or motherhood. The results were compared across coders for inter-reliability and included in this paper to illustrate the unique experiences homeless mothers face. The first names used in this report are fictional.

\section{Samples}

Because of the nature of our sampling design, we have provided results from three separate sub-samples: baseline interviews, longitudinal interviews (Waves 2-13), and the final contact interview. Each of these subsamples is described in detail below.

Sub-Sample A-At baseline, a total of 241 young women were interviewed. Our baseline sample consisted of 222 sexually active female adolescents who were asked questions about their history of pregnancy. Of these women, 103 had experienced a pregnancy and answered subsequent questions on pregnancy and childbirth. Thus, our baseline sample consists of the 103 women who had experienced a pregnancy.

Sub-Sample B-Our longitudinal sample consists of 171 women who had viable data from baseline contact and at least one follow-up wave of our study. Longitudinal data from Kansas City was deleted from the sample because of the termination of the interviewer at that location which resulted in loss of multiple waves of data after baseline data collection (Kansas City was included in the baseline descriptives). In total, 41 women were deleted from longitudinal data because they were from the Kansas City sampling frame. In total, 29 women were deleted in our longitudinal analyses because they only had viable data at 
baseline. Of the 171 women who were interviewed at baseline and a follow-up wave, 83 young women answered questions indicating that they had became pregnant at some point between Waves 2-13 which we will refer to as Subsample I (see Table 2 and Table 4). In total, 90 women answered that they had children at some point between Waves 2-13 which we will refer to as Subsample II (see Table 3).

Sub-Sample C-Our final table is based on data from our final contact at Wave 13. In all, 114 women (excluding Kansas City) were interviewed at Wave 13. Of the 114 women who were interviewed at Wave 13, 68 reported having had children. Of the 68 women who reported having children, 36 women reported having custody of their children (see Table 5)

\section{Results}

\section{Descriptives of Baseline Sample}

Of the 222 sexually active women asked if they were pregnant at baseline (Wave 1), almost half $(46.4 \%)$ stated they had ever been pregnant $(n=103)$. In order to contextualize the experiences of these young homeless women who had been pregnant at their baseline interview we have included some background demographic information about their lives. Half of the young women who had been pregnant are white, 20\% are African American, and almost ten percent $(8.7 \%)$ are Latino. Fifteen percent identified themselves as biracial, and the remaining women self-identified as Native. No respondents identified themselves as Asian or Asian-American. Over half of these women (55.3\%) left home before age 14.

The circumstances surrounding their leaving home were diverse. Only 3 women reported they were kicked out because of pregnancy. One young woman reported she left because her home was not safe for her baby and two more women reported leaving because they were scared to tell their caretakers they were pregnant or they left with their children's fathers. The majority of youth reported leaving because of abuse or conflict. Interestingly, when directly asked, $64 \%$ of these young women reported being kicked out at some point by a caretaker and $36 \%$ reported they have been stopped from going home by a parent or other adult. Three-fourths of these young women left their parents' home when they ran away for the first time, as opposed to foster care or other living situations. Over half of the young women reported living in a big city when they left home $(100,000+)$ and less then $20 \%$ reported leaving from a small town or country setting.

Two thirds of these young women had experienced physical victimization at baseline with almost one half (46.6\%) experiencing sexual victimization. The majority $(71.3 \%)$ had dropped out of school by Wave 1 even after reporting good grades in school (52\% reported A's or B's and $40 \%$ reported C's). Approximately $30 \%$ of the young women told us they had been in a special education class and almost $40 \%$ reported being suspended three or more times.

The young women's living situations since leaving home had been tumultuous. Sixty seven percent reported ever living in a shelter, almost $60 \%$ reported ever living in a group home and $45 \%$ reported living in a foster home at some point in their lives. Over a third reported spending time in juvenile detention and $16.5 \%$ reported staying in a hospital or other facility for substance use. Four out of ten of the women reported staying in a hospital or facility for mental health treatment and almost half $(46.6 \%)$ had spent time directly on the street. Among young women who had lived on the street, over one-fourth had done so by age 13, one-third had spent at least a week on the street, and half had experienced multiple episodes of living on the street. 


\section{Descriptive Results of Pregnancies at Baseline}

Table 1 shows descriptive statistics for the baseline sub-sample of women who had experienced pregnancy. Of the young women who had ever been pregnant at baseline $(\mathrm{n}=103), 55.3 \%$ had been pregnant once, $31.1 \%$ had been pregnant twice and $13.5 \%$ had been pregnant three or more times. The women stated they were between the ages of 12 and 18 years when they first became pregnant with an average age of 15.25 years at first pregnancy.

Among the 103 young women who stated they had ever been pregnant at baseline, thirteen were still pregnant at Wave 1, eleven reported having an abortion, forty-two reported a miscarriage and seven reported giving their child up for adoption. In all, only thirty young women went to term with their pregnancy without intent for adoption. Among these young women, almost all reported their child was living with family members (not shown in tables). Half of these young women $(n=15)$ reported their baby was living with their or their partners' parents (i.e. mothers, fathers, stepmothers, mother-in-laws), four reported their grandmothers were taking care of their child, and three reported that their child lived with another family member (i.e. aunt, uncle, sibling). Two young women reported their child had been placed in foster care. We were unable to ascertain if these were voluntary or involuntary placements. Four young women reported that their children lived with them, and of these, two had their child with them in a group home or shelter.

The uncertainty surrounding living arrangements for mothers who are homeless and their children was evident in the in-depth interviews. Allison, (a 20 year old new mother) told us that she had moved back home with her mother after her baby was born. Katie (19 years and pregnant) stated she and her two children had moved back in with her mother, and Rachel (20 years and pregnant) was staying with family. Lindsey (19 years and pregnant) was staying at her boyfriend's uncle's house where she was paying rent. Amy (19 years old) told us that she had an apartment. "The only way I got an apartment was because I went through Section 8 . Section 8 is paying my rent and the only reason why I was able to get on Section [8] was because I have a son."

The impacts of living apart from children were discussed as well. Sarah (20 years) spoke at length about her one year old son who was living with her mother in Minneapolis. Mary (21 years old and pregnant) talked extensively about losing her children because of an abusive relationship and trouble with the law. When asked why she didn't have her children with her she stated: "because some guy I was dating... was watching my kids and I got a call... saying that my son was hurt, and I had to go home and get him and take him to the hospital and found out he broke my sons' arm, and the next day they took the, my two kids away, and they've been gone ever since." She also stated her infant son was taken away only a few months earlier because she was ordered to serve time in jail for an outstanding warrant.

\section{Pregnancies across Time}

Over the three years of data collection we saw 171 different women at least once after baseline interview (Waves 2-13). Of the 171 women contacted after baseline, 83 reported being pregnant at some point during the three years (See description of Subsample I in Methods Section). These eighty-three young women (48.5\%) reported 104 different pregnancies. Twenty women reported becoming pregnant twice and one woman reported she had been pregnant three times. Nearly all of these women planned on keeping and raising their babies, either alone or with partners. Only one woman planned on an abortion and only three women mentioned planning on an adoption (although two of these women reported keeping the baby at later waves). Three women told us that their partner would raise the baby after it was born, and one woman stated that her family would take the baby. 
Thirteen of the young women had not made a decision on the outcome for the pregnancy at the time of their interview. None of the young women who were part of the in-depth interviews discussed abortion or adoption as options for their most recent pregnancy.

\section{Characteristics of the Pregnant Women across Time}

The following descriptive characteristics are based on the 83 young women who answered that they had been pregnant between Waves 2 and 13 (See description of Subsample I in Methods section). Among the women who were pregnant at any given wave of interviews, thirty-one reported having other children. Ten of the women told us they had lived on the streets while pregnant or in the months just prior to becoming pregnant. None of the women reported trading sex during the months prior to conception and only four women reported drinking alcohol at a time when they could have been pregnant.

Fifty-seven of the young women reported receiving public assistance and forty-nine of the women had a job while pregnant or shortly before becoming pregnant. Rachel discussed the difficulty of qualifying for assistance in detail. She told us that she was on Medicaid to help with medical expenses while pregnant and that she was waiting to be approved for nutritional help from the Women, Infants, \& Children Program (WIC). To be eligible, she had forged her address because her mother was receiving assistance as well. Sarah told us about the difficulties of employment when pregnant. She had worked at an adult book store until 2:30 in the morning while six months pregnant. Mary, who had lost custody of her children because of events that happened while she was at work, was pregnant again at the time of her interview. She was not currently employed because of past pregnancy complications (premature labor at 5 months).

Of the 49 pregnant women who reported that they could go home to live with their parents if they wanted to, only 17 reported they would do so. The difficulties of moving back home were apparent in Allison's in-depth interview. She told us that moving back home was difficult because "of the rules and stuff" but she did so anyway for her baby. Not only was independence an issue for many of the young women, but prior and current abuse at the hands of caretakers played an important role in whether or not young mothers returned home after giving birth. Amy stated: "My mom, I don't care for her too much... when I first got pregnant with my son, I tried to move in there with her and she would come back at three [or] four in the morning drunk, and I'd have to be to work at five, and she would hit me and stuff... It almost made me lose [my son]..."

\section{Partner Abuse}

Although we did not assess partner violence in the quantitative questionnaire, there were several accounts of intimate partner violence in the in-depth interviews. Mary told us that: “.. he'd come home from work and accuse me of going somewhere and then he'd start hitting me or cause at that time I had an infant plus I was pregnant and so sometimes the house would be messy and he'd come home and start yelling and then he'd end up hitting me or he'd come home drunk and start hitting me..... I went to the hospital quite a few times.... I mean I was pregnant and they were concerned about the baby..."

Sarah said her boyfriend physically abused her while pregnant. "He had me by the throat, up against the wall...I had choke marks on my neck and he almost broke, he had dislocated my ankle by putting me in an ankle lock. I just had bruises all over me... he ended up putting his knee right here on my neck [by] the vein, and pinned me on the ground and said that he was going to kill me." Sarah's son was born with many health problems, including blindness, possible mental retardation, heart and kidney problems, and multiple sclerosis. 
Amy also stated that her boyfriend abused her "he used to hit me all the time... and he's tried to kill me... and he would just do things that would hurt me emotionally."

\section{Custody and Visitation}

Table 3 provides descriptive information of the young mothers' relationships with their children. Of the 171 women who we interviewed at least once after baseline (Waves 2-13), ninety (52.6\%) reported having children (not shown in tables). Of the 90 young women who reported they had children at some point over the three years, 50 told us they had custody of their children every time they were interviewed. Seventeen mothers reported never having custody of their children and twelve reported losing custody of their children over the course of the study. Ten of the women sporadically had custody of their children in multiple encounters with the child welfare system. Only one of the women who had lost custody of her children regained it.

Mary discussed her involvement with the child welfare system in detail during the in-depth interviews. When asked what she needed to do to get her children back she stated: "I have to go to counseling... I have to take domestic violence classes, due to [a] previous, uhm, domestic relationship... have to visit my kids... individual therapy... I am doing the things I am supposed to be doing and, I mean everybody sees that. You know there is no reason why I can't get them back..."

Among the 40 young women who ever reported they did not have custody of their children over the three years (Waves 2-13), about one-half reported they consistently helped care for them over the course of the study. Ten women stated they never helped care for their children at any wave of data collection and ten women reported they helped care for their children at intermittent waves. When asked how often they saw their children, only 4 of the 40 noncustodial mothers said they saw their children nearly everyday. Eight young women told us they almost never saw their children. The remaining 28 mothers saw their children irregularly, sometimes weekly, sometimes monthly.

Losing custody of their children had emotional consequences for these young women. When asked about negative things in her life, Mary stated that not getting to see her kids everyday was difficult and she was "working on that right now to get all the things done that I need to get done so I can start seeing them more so I have more time for them". Sarah, whose son lived in Minneapolis with her mother, stated that something positive in her life was that she finally got into the YWCA and she would be able to have her son move in with her.

\section{Mental Health and Motherhood}

Table 4 provides descriptive information about mental health at baseline and pregnancy across time. A majority of the young women who became pregnant across the three years of our study met criteria for lifetime mental or substance use disorders at baseline. Of the 83 women who reported becoming pregnant at least once after baseline, approximately onethird (32.5\%) had a history of major depressive episode. Almost two-thirds of the women who became pregnant over the three years of the study had histories of conduct disorder at baseline $(65.1 \%)$ and over half $(51.8 \%)$ had histories of post-traumatic stress disorder. Some of the young women discussed mental health issues in their in-depth interviews. For example, Sarah told us that: "[I have] continue[ed] with my counseling.... I've continued taking my anti-depressants.......... and I've been trying to keep away from the people that have you know brought me down when I first came [here]." Mary said she struggles with depression sometimes because she does not have custody of her children.

Over one-third of the young women met lifetime criteria for drug abuse at baseline (34.9\%). Sarah stated she was using pot everyday and crank at least three or four times a week, but 
she says her drug use "continued for like a year until I found out I was pregnant then I stopped completely." Lindsey, a former crack user stated, "Once I found out I was [pregnant] I was like forget it and I stopped [using]. I stopped smoking anyway because I don't want to lessen no baby's life because of what I do...I've seen how a lot of babies end up when their mom is gone off of drugs when their mom is pregnant and stuff like that and I don't want my baby, I want my baby to be healthy and I don't want my baby taken away from me."

Less than five percent of the young women reported using alcohol when they were pregnant or when they may have been pregnant (see Table 2). Yet, $41 \%$ of women met lifetime criteria for alcohol abuse and almost one-fourth of women met lifetime criteria for alcohol dependence $(22.9 \%)$ at baseline. Rachel stated that she did use alcohol while pregnant, only reporting one incident: "They were all getting drunk and stuff and I went to leave, he was trying to make me drink and stuff and I did drink, I had to drink, I drank a little bit. I drank like one shot and then they kept getting me to drink some more and then finally I think I had two and a half shots that whole night because they kept on pressuring me into doing it and I did it and then finally I was like I can't do it no more I need to go home I need to go to sleep, my stomach hurts and stuff like that. I was pregnant then so that's why my stomach was hurting but I was only like a month or something then like a month and a half."

\section{Mental Health and Motherhood at Final Contact}

To further investigate mental health we looked at lifetime and 12-month mental and substance use disorders among young mothers at the final wave (Wave 13) of the three-year study. In total, 114 young women were interviewed at Wave 13. Of these 114 women, 68 reported having had children. Of the 68 women with children, only 36 reported having custody of their children (not shown on table). Among women who had reported ever having children, over a fourth (26.5\%) met criteria for both lifetime and 12-month major depressive disorder at Wave 13. Two-thirds of the young mothers (66.2\%) met criteria for lifetime antisocial personality disorder, and more than one-half (57.4\%) met criteria for 12-month antisocial personality disorder. Approximately $40 \%$ met lifetime criteria for post-traumatic stress disorder (PTSD) and 16.2\% met 12-month criteria for PTSD. Over a quarter of women $(27.9 \%)$ met lifetime criteria for drug abuse, and $13.2 \%$ met 12-month criteria for drug abuse. More than one-fifth of the mothers met either lifetime (23.5\%) or 12-month $(22.1 \%)$ criteria for alcohol abuse. Nine women (13.2\%) met criteria for either lifetime or 12-month alcohol dependence.

Because so many of the young women who had given birth met criteria for mental health disorders, we decided to investigate the prevalence of disorders among women who reported having custody of their children at Wave 13. Almost one-third (30.6\%) of women with children living with them met criteria for either lifetime or 12-month major depressive episode. Fifty-eight percent of mothers with children in their care met lifetime criteria for antisocial personality disorder, with $47.2 \%$ meeting 12 -month criteria for antisocial personality disorder. A third of young women caring for children (36.1\%) met lifetime criteria for PTSD, with 11.1\% meeting 12-month criteria for PTSD. Almost one-third of mothers with custody of their children (30.6\%) met lifetime criteria for drug abuse but only two women met criteria for 12-month drug abuse (5.6\%). Less than $20 \%$ met criteria for lifetime (19.4\%) or 12-month (16.7\%) alcohol abuse. About $10 \%$ met either lifetime or 12month criteria for alcohol dependence $(8.3 \%)$.

\section{Thoughts about the Future}

Many of the women viewed their pregnancies as a chance to make positive changes. For example, Allison told us, "If it wasn't for my son I'd probably be out on the streets right 
now getting high, not caring what I was doing. Cause then I didn't care. If I died I didn't care.... Now I care cause now I have him....I could stay focus[ed] now... for my baby. I think I am pretty satisfied [with my life] because I think I'm gonna do something good..."

Katie said that she was proud of her son and said that they are a "package deal". Lindsey said, "Well I know that getting pregnant changed me... I want my baby to be healthy... [I have to] take care of myself and the baby..." When asked about positive things in her life, Sarah stated that being able to have her son move in with her and having a safe place for him to live were good things. When asked who she spends time with now, Amy said: "My son, he's one years old and we have fun, we play, and we cry, and we take walks and everything..." The impact of sustaining a pregnancy and raising children was seen as a positive challenge that improved the women's lives. As Rachel put it: "[I want to] help out people, to be different than what I was when I was younger... I think I'd be good with kids, talking about their problems and stuff now that I have had so many..."

\section{Discussion}

By the last interview, more than two-thirds (68.4\%) of the 171 young women who we had contact with at least once after baseline had been pregnant. This is more than five times the pregnancy rate (12.6\%) for 18-19 year old women in the U.S. as a whole (Guttmacher Institute, 2006). There has been very little research that addresses pregnancies specifically among young homeless women, so in discussing our findings, we draw on research regarding pregnancies among homeless women without regards to age. We believe that the risks are likely very similar or exacerbated among young women who are homeless and pregnant as for those who are somewhat older.

Women who are homeless represent the highest conception and pregnancy risks in our nation. The women may use alcohol, tobacco or drugs before they are aware they are pregnant or during pregnancy. A substantial number of young mothers who are homeless suffer from mental disorders such as major depression, PTSD, and substance use. As many as two-thirds of those with mental disorders have two or more disorders (Bassuk et al., 1998). Sexual partners may be substance users and the women are at high risk for contracting STIs. Access to prenatal care without the help of Medicaid is difficult and nutrition is an ongoing and often overlooked problem among young homeless people (Whitbeck, Chen, \& Johnson, 2006). Babies who are born to mothers who are homeless are at a very high risk for low birth weight, medical complications, and developmental problems (Chapman et al., 2007; Little et al., 2005; Stanwood \& Levitt, 2004; Stein, Lu, \& Gelberg, 2000). As they grow, these children are at risk for health problems (Wright, Rubin \& Devine, 1998), problems with school adjustment, educational delays (Powers \& Jaklitsch, 1993; Rubin et al., 1996), and developmental delays (Bassuk \& Rosenberg, 1990; Fox, Barrnett, Davies, \& Bird, 1990). Children may develop aggressive tendencies as an adaptive response (externalization) or may exhibit depressive symptoms (internalization) in response to homelessness (Bassuk \& Rosenburg, 1990; Kupersmidt et al., 1995, Rabideau \& Toro, 1997).

Often the child will be born into the revolving door life of a young mother who is homeless (Whitbeck \& Hoyt, 1999; Whitbeck, 2009). Without welfare support the mother is unlikely to be able to obtain stable housing. Even prior to the subprime mortgage crisis the National Low-Income Housing Coalition concluded that our country is experiencing a prolonged shortage of affordable housing. A full time worker at minimum wage cannot afford a one bedroom unit at Fair Market Rent anywhere in the U.S. (National Low-Income Housing Coalition, 2008). The recent subprime mortgage crisis portends special risk for housing instability among low-income women, particularly single mothers who are renters. 
According to CBS News reports based on Realty-Trac Data, 38\% of foreclosures nationwide involve rental properties (cited in Erlenbusch, O'Connor, Downing, \& Watlov-Phillips, 2008). Existing affordable rental properties cannot meet the current demand for housing.

These findings also indicate that many of these young women will have difficulty parenting due to mental health issues (Whitbeck, Johnson, Hoyt, \& Cauce, 2004). Symptoms of depression, PTSD, histories of externalizing behaviors, and substance abuse indicate potential problems these young mothers may have providing positive parenting and a stable environment. Research suggests that mothers who are homeless may be significantly less likely than mothers who are housed to provide their children with structure, academic stimulation, and warmth and acknowledgment (Koblinsky, Morgan, \& Anderson, 1997). The lack of routine and lack of supervision related to being homeless may add to the high levels of externalized behaviors exhibited by homeless children (Rabideau \& Toro, 1997).

Furthermore, research indicates that parental antisocial behavior is indicative of conduct problems among their offspring (Lahey et al., 1988; Rhule, McMahon \& Spieker, 2004). Yehuda and colleagues (2002) found that children are more likely to develop PTSD if they had a parent who suffered from chronic PTSD, suggesting that children of traumatized parents are at high risk for developing symptoms when exposed to traumatic events. Research has consistently shown maternal depression influences the psychological wellbeing of children (see reviews by Cummings \& Davies, 1999; Elgar, McGrath \& Waschbusch, 2004).

Although these findings represent unique data pertaining to pregnancies among young women who are homeless, there are some limitations to the current study that should be taken into consideration. First, our sample is not a random sample of homeless youth and results may not be generalizable to all homeless youth, especially those residing outside the Midwest. Second, we rely on self-report data and there may be a tendency to under report undesirable behaviors such as substance use during pregnancy. In addition, baseline data are retrospective and may suffer from problems of recall of specific events. Not recalling something as life changing as an early pregnancy, however, is unlikely. Third, the wording of the pregnancy question was "Are you pregnant?" This would miss respondents who had been pregnant since the prior three-month interview and who had miscarried or sought an abortion. Fourth, we were unable to ascertain if behaviors reported by respondents were while they were cognizant of their pregnancy or during early gestation. Fifth, we were unable to link the qualitative respondents to those in our larger quantitative study because the identification numbers in the two separate data collections did not match. Sixth, these findings are limited to women who were aged approximately 22 years or younger when pregnant and may not reflect the characteristics and experiences of older homeless women who become pregnant. Finally, many of our respondents attrited during the three years of data collection. Just over 19\% of our sample never completed a follow-up interview, therefore are only included in the baseline sub-sample. We have structured our longitudinal data analysis so that respondents needed two waves of data at any point during the three years to maximize information. By our final wave of data collection, Wave 13, we had lost $54 \%$ of our sample (Whitbeck, 2009). There were few significant differences between individuals who attrited from our study and those who stayed. Those who left the study after the first interview were younger, spent less time on their own, and were less likely to have experience severe trauma (Whitbeck, 2009).

\section{Conclusions and Implications for Practice}

These findings describe the most at-risk young mothers in our society. Becoming pregnant during adolescence is a tremendous stressor for young women who have family and peer 
support, access to prenatal care, and a supportive partner. These young women lack even a stable place to live. The likelihood of birth complications, low weight infants, problems with parenting, and long range developmental problems are very great. Although many street outreach workers are already working closely with young women who are homeless around issues of contraception and risk for STIs, including home pregnancy test kits as part of "survival kits" or making the testing packets available at drop-in centers and shelters free of charge is an important but simple policy consideration. Many of the young women told us that once they knew they were pregnant they changed their substance use behaviors. Early detection is an important first step.

Besides early detection, immediate referral for existing welfare programs that would provide prenatal care and nutrition is also important. It is very possible that young women have gone months already without medical care and adequate diets for optimal fetal development. This welfare support may be the only way to get them off the streets and out of shelters into subsidized housing. In addition to finding permanent supportive housing, programs which provide childcare while promoting employment opportunities and educational training, such as GED and college placement, are keys to keeping homeless mothers off the street. Finally, innovative mentoring programs are needed that bring together supportive older women and pregnant young women who are homeless. Pregnancy is scary for young women who are homelessness. Just being homeless is incredibly stressful and becoming pregnant greatly exacerbates this stress. They have very few resources and many have no where to turn. Young women who are homeless already have a history of not making the best decisions, many have mental health problems such as depression and externalizing behaviors, and some are responding to the effects of trauma. Many have lost ties to mentoring adults (Whitbeck, 2009) who are critical sources of information support, and reassurance for women during pregnancy and birth. Mentorship programs would fill the important social role of mentoring from older women who have experienced pregnancy and birth. These programs could be linked to existing nutrition, and medical care programs, could be largely volunteer and may increase levels of compliance with prenatal care. The cost benefits of such comparably inexpensive interventions could greatly exceed the expense of such programs in terms of long-term service burden for mothers and children.

\section{Acknowledgments}

We want to thank Dr. Kimberly Tyler for allowing us access to her qualitative data collected through a University of Nebraska-Lincoln faculty seed grant. Also thanks to the anonymous reviewers for their helpful comments. This research was funded by the National Institute of Mental Health (MH57110), Les B. Whitbeck, Principal Investigator.

\section{References}

Arangua L, Andersen R, Gelberg L. The health circumstances of homeless women in the United States. International Journal of Mental Health. 2005; 34:62-92.

Bassuk EL, Buckner JC, Perloff JN, Bassuk SS. Prevalence of mental health and substance use disorders among homeless and low-income housed mothers. American Journal of Psychiatry. 1998; 155:1561-1564. [PubMed: 9812118]

Bassuk EL, Rosenberg L. Psychosocial characteristics of homeless children and children with homes. Pediatrics. 1990; 85:257-261. [PubMed: 2304777]

Bassuk EL, Weinreb L. Homeless pregnant women: Two generations at risk. American Journal of Orthopsychiatry. 1993; 63:348-357. [PubMed: 8372902]

Burt, MR. Homelessness: Definitions and counts. In: Baumohl, J., editor. Homelessness in America. Phoenix: Oryx; 1996a. p. 15-23.

Burt, MR. Practical methods for counting homeless people: A manual for state and local jurisdictions. 2nd ed.. Washington, D.C.: Urban Institute; 1996b. 
Cauce AM, Paradise M, Ginzler JA, Embry L, Morgan CJ, Lohr Y, Theofelis J. The characteristics and mental health of homeless adolescents. Journal of Emotional and Behavioral Disorders. 2000; 8:230-239.

Center on Budget and Policy Priorities. Census data show poverty increased, income stagnated, and the number of uninsured rose to a record level in 2003. 2004. Retrieved on November 3, 2008, from http://www.cbpp.org/8-26-04pov.htm

Chapman K, Tarter RE, Kirisci L, Cornelius MD. Childhood neurobehavior disinhibition amplifies risk of substance use disorder: Interaction of parental history and prenatal alcohol exposure. Journal of Developmental and Behavioral Pediatrics. 2007; 28:219-224. [PubMed: 17565289]

Culhane JF, Webb D, Grim S, Metraux S, Culhane D. Prevalence of child welfare services involvement among homeless and low-income mothers: A five-year birth cohort study. Journal of Sociology and Social Welfare. 2003; 30:79-96.

Cummings, EM.; Davies, PT. Depressed parents and family functioning: Interpersonal effects and children's functioning and development. In: Joiner, T.; Coyne, J., editors. The interactional nature of depression. Washington, D.C.: American Psychological Association; 1999. p. 299-327.

Duffield B. The Educational Rights of Homeless Children: Policies and Practices. Educational Studies. $2001 ; 32: 324$.

Elgar FJ, McGrath PJ, Waschbusch DA, Stewart SH, Curtis LJ. Mutual influences on maternal depression and child adjustment problems. Clinical Psychology Review. 2004; 24:441-459. [PubMed: 15245830]

Erlenbusch, B.; O'Connor, K.; Downing, S.; Watlov-Phillips, S. Foreclosure to homelessness: The forgotten victims of the subprime crisis: A national call to action. Washington, D.C.: National Coalition for the Homeless; 2008.

Fox SJ, Barrnett RJ, Davies M, Bird HR. Psychopathology and developmental delay in homeless children: A pilot study. Journal of the American Academy of Child and Adolescent Psychiatry. 1990; 29:732-735. [PubMed: 1699926]

Gelberg, L.; Andersen, R.; Wenzel, S.; Leake, B.; Sumner, G. Homeless women's use of birth control and women's health services. Abstract Book of the Association for Health Services Research Meeting. 1999. 1999; 16: 150-1. Retrieved on November 1, 2008, from http://gateway.nlm.nih.gov/MeetingAbstracts/ma?f=102194560.html.

Gelberg L, Lu MC, Leake BD, Andersen RM, Morgenstern H, Nyamathi AM. Homeless women: Who is really at risk for unintended pregnancy? Maternal Child Health Journal. 2008; 12:52-60.

Greene JM, Ringwalt CL. Pregnancy among three national samples of runaway and homeless youth. Journal of Adolescent Health. 1998; 23:370-377. [PubMed: 9870331]

Guttmacher Institute. U.S. teenage pregnancy statistics: National and state trends and trends by race and ethnicity. New York: Guttmacher Institute; 2006.

Hagen, J.; McCarthy, B. Mean streets: Youth crime and homelessness. New York, NY: Cambridge University Press; 1997.

Halcón LL, Lifson AR. Prevalence and predictors of sexual risks among homeless youth. Journal of Youth and Adolescence. 2004; 33:71-80.

Haley N, Roy E, Leclerc P, Boudreau JF, Boivin JF. Characteristics of adolescent street youth with a history of pregnancy. Journal of Pediatric Adolescent Gynecology. 2004; 17:313-320. [PubMed: 15581776]

Hammer, H.; Finkelhor, D.; Sedlak, AJ. National Incidence Studies of Missing, Abducted, Runaway and Thrownaway Children (NISMART Bulletin Series). Washington, DC: U.S. Department of Justice, Office of Justice Programs, Office of Juvenile Justice and Delinquency Prevention; 2002. Runaway/thrownaway children: National estimates and characteristics. Retrieved January 12, 2005, from www.ncjrs.org/pdffiles1/ojjdp/196469.pdf.

Health Resources and Services Administration, U.S. Department of Health and Human Services. Program Assistance Letter: Understanding the Health Care Needs of Homeless Youth. 2001. Available free at http://bphc.hrsa.gov/policy/pal0110.htm.

Janus MD, Archambault FX, Brown SW, Welsh LA. Physical abuse in Canadian runaway adolescents. Child Abuse \& Neglect. 1995; 19:433-447. [PubMed: 7606522] 
Kaufman JG, Widom CS. Childhood victimization, running away, and delinquency. Journal of Research in Crime and Delinquency. 1999; 36:347-370.

Kennedy MR. Homeless and runaway youth mental health issues: No access to the system. Journal of Adolescent Health. 1991; 12:576-579. [PubMed: 1772899]

Kipke, MD.; O'Connor, S.; Nelson, B.; Anderson, J. A probability sampling for assessing the effectiveness of outreach for street youth. In: Greenberg, J.; Neumann, M., editors. What we have learned from the AIDS evaluation of street outreach projects: A summary document. Atlanta: Department of Health and Human Services, Centers for Disease Control and Prevention; 2000.

Koblinsky SA, Morgan KM, Anderson EA. African American homeless and low income housed mothers: Comparison of parenting practices. American Journal of Orthopsychiatry. 1997; 6:37-47. [PubMed: 9034020]

Koegel P, Burnam MA, Morton SC. Enumerating homeless people: Alternative strategies and their consequences. Evaluation Review. 1996; 20:378-403.

Kupersmidt JB, Griesler PC, DeRosier ME, Patterson CJ, Davis PW. Childhood aggression and peer relations in the context of family and neighborhood factors. Child Development. 1995; 66:360 375. [PubMed: 7750371]

Kurtz PD, Kurtz GL, Jarvis SV. Problems of maltreated runaway youth. Adolescence. 1991; 26:544555.

Lahey BB, Piacentini JC, McBurnett K, Stone P, Hartdagen SE, Hynd GW. Psychopathology and antisocial behavior in the parents of children with conduct disorder and hyperactivity. Journal of the American Academy of Child and Adolescent Psychiatry. 1988; 27:163-170. [PubMed: 3360717]

Little M, Shah R, Vermeulen MJ, Gorman A, Dzendoletas D, Ray JG. Adverse perinatal outcomes associated with homelessness and substance use in pregnancy. Canadian Medical Association Journal. 2005; 173:615-618. [PubMed: 16157725]

Markos PA, Lima NR. Homelessness in the United States and its effect on children. Guidance and Counseling. 2003; 18:118-124.

Meadows-Oliver M. Mothering in public: A meta-synthesis of homeless women with children living in shelters. Journal for Specialists in Pediatric Nursing. 2002; 8:130-136. [PubMed: 14677319]

Molnar BE, Shade SB, Kral AH, Booth RE, Watters JK. Suicidal behavior and sexual/physical abuse among street youth. Child Abuse \& Neglect. 1998; 22:213-222. [PubMed: 9589175]

Mounier C, Andujo E. Defensive functioning of homeless youth in relation to experiences of child maltreatment and cumulative victimization. Child Abuse and Neglect. 2003; 27:1187-1204. [PubMed: 14602099]

National Coalition for the Homeless. Why are people homeless?: NCH Fact Sheet \#1. 2008a. Retrieved on November 21, 2008, from http://www.nationalhomeless.org/publications/facts/why.html.

National Coalition for the Homeless. Homeless Families with Children: NCH Fact Sheet \#12. 2008b. Retrieved on November 21, 2008, from http://www.nationalhomeless.org/publications/facts/families.html.

National Coalition for the Homeless. Homeless Youth: NCH Fact Sheet \#13. 2008c. Retrieved on November 21, 2008, from http://www.nationalhomeless.org/publications/facts/youth.pdf.

National Institute of Health. Code of Federal Regulations Title 45, Public Welfare. Part 46 - Protection of Human Subjects (45 CFR 46.117). Department of Health and Human Services: Office for the Protection from Research Risks; 2005. Retrieved July 22, 2008, from http://www.hhs.gov/ohrp/humansubjects/guidance/45cfr46.htm.

Noell J, Rohde P, Seeley J, Ochs L. Childhood sexual abuse, adolescent sexual coercion and sexually transmitted infection acquisition among homeless female adolescents. Child Abuse \& Neglect. $2001 ; 25: 344-353$.

Nunez, R. Hopes, dreams and promise: The future of homeless children in America. New York, NY: Institute for Children and Poverty, Homes for the Homeless Inc.; 1994.

Nunez R, Fox C. A Snapshot of Family Homelessness across America. Political Science Quarterly. 1999; 114:289-307. 
Oliveira N, Goldberg J. The nutrition status of women and children who are homeless. Nutrition Today. 2002; 37:70-77. [PubMed: 11984436]

Patterson GR, Dishion TJ, Bank L. Family interaction: A process model of deviancy training. Aggressive Behavior. 1984; 10:253-267.

Pennbridge JN, Yates GL, David TG, MacKenzie RG. Runaway and homeless youth in Los Angeles County, California. Journal of Adolescent Health Care. 1990; 11:159-165. [PubMed: 2318715]

Powers JL, Jaklitsch B. Reaching the hard to reach: Educating homeless adolescents in urban settings. Education and Urban Society. 1993; 25:394-409.

Rabideau JMP, Toro PA. Social and environmental predictors of adjustment in homeless children. Journal of Prevention and Intervention in the Community. 1997; 15:1-17.

Rhule DM, McMahon RJ, Spieker SJ. Relation of adolescent mothers' history of antisocial behavior to child conduct problems and social competence. Journal of Clinical and Adolescent Psychology. 2004; 33:524-535.

Ringwalt CL, Greene JM, Robertson M, McPheeters M. The prevalence of homelessness among adolescents in the United States. American Journal of Public Health. 1998; 88:1325-1329. [PubMed: 9736871]

Rotheram-Borus MJ, Mahler KA, Koopman C, Langabeer K. Sexual abuse history and associated multiple risk behavior in adolescent runaways. American Journal of Orthopsychiatry. 1996; 66:390-400. [PubMed: 8827262]

Rubin DH, Erickson CJ, San Agustin M, Cleary SD, Allen JK, Cohen P. Cognitive and academic functioning of homeless children compared with housed children. Pediatrics. 1996; 97:289-294. [PubMed: 8604259]

Rutter, M.; Quinton, D.; Hill, J. Adult outcome of institution-reared children: Males and females compared. In: Robbins, L.; Rutter, M., editors. Straight and deviant pathways from childhood to adulthood. Cambridge, UK: Cambridge University Press; 1990. p. 135-157.

Ryan KD, Kilmer RP, Cauce AM, Watanabe H, Hoyt DR. Psychological consequences of child maltreatment in homeless adolescents: Untangling the unique effects of maltreatment and family environment. Child Abuse \& Neglect. 2000; 24:333-352. [PubMed: 10739077]

Stanwood GD, Levitt P. Drug exposure early in life: Functional repercussions of changing neuropharmacology during sensitive periods of brain development. Current Opinion in Pharmacology. 2004; 4:65-71. [PubMed: 15018841]

Stein JA, Lu MC, Gelberg L. Severity of homelessness and adverse birth outcomes. Health Psychology. 2000; 19:524-534. [PubMed: 11129355]

Sullivan PM, Knutson JF. The prevalence of disabilities and maltreatment among runaway children. Child Abuse \& Neglect. 2000; 24:1275-1288. [PubMed: 11075695]

Tischler V, Rademeyer A, Vostanis P. Mothers experiencing homelessness: Mental health, support, and social care needs. Health and Social Care in the Community. 2007; 15:246-253. [PubMed: 17444988]

Tyler KA, Hoyt DR, Whitbeck LB, Cauce AM. The impact of childhood sexual abuse on later sexual victimization among runaway youth. Journal of Research on Adolescence. 2001; 11:151-176.

Tyler KA, Whitbeck LB, Hoyt DR, Cauce AM. Risk factors for sexual victimization among male and female homeless and runaway youth. Journal of Interpersonal Violence. 2004; 19:503-520. [PubMed: 15104858]

U.S. Conference of Mayors. A status report on hunger and homelessness in America's cities: A 23-city survey. The United States Conference of Mayors; 2007. Retrieved November 22, 2008, from http://www.usmayors.org/HHSurvey2007/hhsurvey07.pdf.

Wagner JD, Menke EM. Substance use by homeless pregnant mothers. Journal of Health Care for the Poor and Underserved. 1992; 3:1049-2089.

Webb DA, Culhane J, Metraux S, Robbins JM, Culhane D. Prevalence of episodic homelessness among adult childbearing women in Philadelphia, Pa. American Journal of Public Health. 2003; 93:1895-1896. [PubMed: 14600062]

Weinreb L, Goldberg R, Perloff J. Health characteristics and medical service use patterns of sheltered homeless and low-income housed mothers. Journal of General Internal Medicine. 1998; 13:389_ 397. [PubMed: 9669568] 
Whitbeck, LB. Mental health and emerging adulthood among homeless young people. New York: Psychology Press; 2009.

Whitbeck, LB.; Hoyt, DR. Nowhere to grow: Homeless and runaway adolescents and their families. Hawthorne, NY: Aldine de Gruyter; 1999.

Whitbeck LB, Chen X, Johnson KD. Food insecurity among runaway and homeless adolescents. Public Health Nutrition. 2006; 9:47-52. [PubMed: 16480533]

Whitbeck LB, Johnson KD, Hoyt DR, Cauce AM. Mental disorder and comorbidity among runaway and homeless adolescents. Journal of Adolescent Health. 2004; 35:132-140. [PubMed: 15261642]

Whitbeck LB, Simons RL. A comparison of adaptive strategies and patterns of victimization among homeless adolescents and adults. Violence and Victims. 1993; 8:191-204.

Wright, JD.; Rubin, BA.; Devine, JA. Beside the golden door: Policy, politics, and the homeless. Hawthorne, NY: Aldine De Gruyter; 1998.

Yehuda R, Halligan SL, Bierer LM. Cortisol levels in adult offspring of holocaust survivors: Relation to PTSD symptom severity in the parent and child. Psychoneuroendocrinology. 2002; 27:171-180. [PubMed: 11750777]

Zlotnick C, Kronstadt D, Klee L. Essential case management services for young children in foster care. Community Mental Health Journal. 1999; 35:421-430. [PubMed: 10547117]

\section{Appendix A}

Table A

Description of Subsamples

\begin{tabular}{|c|c|c|c|c|}
\hline & Time & Wave(s) & Sample Size & $\mathbf{n}$ for pregnancy and children \\
\hline Table 1 & Baseline $^{a}$ & 1 & 222 & 103 women had ever been pregnant \\
\hline Table 2 & Longitudinal $^{b}$ & $2-13$ & 171 & 83 women had ever been pregnant \\
\hline Table 3 & Longitudinal $^{b}$ & $2-13$ & 171 & 90 women had children \\
\hline Table 4 & Longitudinal $^{b}$ & $2-13$ & 171 & 83 women had ever been pregnant \\
\hline \multirow[t]{2}{*}{ Table 5} & Final Contact ${ }^{c}$ & 13 & 114 & 68 women had children \\
\hline & & & & 36 women had custody of children \\
\hline
\end{tabular}

Am J Orthopsychiatry. Author manuscript; available in PMC 2012 June 26. 
Table 1

Baseline Pregnancy Descriptives ( $n=103)$

\begin{tabular}{|c|c|c|}
\hline & $\mathbf{n}$ & $(\%)$ \\
\hline \multicolumn{3}{|l|}{ Number of Pregnancies } \\
\hline Once & 57 & (55.3) \\
\hline Twice & 32 & (31.1) \\
\hline Three or More & 14 & (13.5) \\
\hline \multicolumn{3}{|l|}{ Age at First Pregnancy } \\
\hline 12 & 7 & $(6.9)$ \\
\hline 13 & 10 & $(9.8)$ \\
\hline 14 & 11 & $(10.8)$ \\
\hline 15 & 28 & $(27.2)$ \\
\hline 16 & 27 & (26.5) \\
\hline 17 & 10 & $(9.8)$ \\
\hline 18 & 10 & $(9.8)$ \\
\hline \multicolumn{3}{|l|}{ Outcomes } \\
\hline Still Pregnant & 13 & (12.6) \\
\hline Abortion & 11 & (10.7) \\
\hline Miscarriage & 42 & $(40.8)$ \\
\hline Adoption & 7 & $(6.8)$ \\
\hline Went to Term & 30 & (29.1) \\
\hline
\end{tabular}


Table 2

Characteristics of Pregnancy Over Time $(n=83)$

\begin{tabular}{lcc}
\hline & n & $(\%)$ \\
\hline Other Children & 31 & $(37.3)$ \\
Living on Street & 10 & $(12.0)$ \\
Trading Sex & 0 & $(0.0)$ \\
Alcohol Use & 4 & $(4.8)$ \\
Receive Public Assistance & 57 & $(68.7)$ \\
Employed & 49 & $(59.0)$ \\
Could Return Home & 49 & $(59.0)$ \\
Will Return Home & 17 & $(20.5)$ \\
Caretaker Sexual Abuse & 5 & $(6.0)$ \\
Cartaker Physical Abuse & 14 & $(16.9)$ \\
Always Used Condoms & 17 & $(20.5)$ \\
Steady Relationship & 50 & $(60.2)$ \\
\hline
\end{tabular}




\section{Table 3}

Children and Motherhood Across Time (n=90)

\begin{tabular}{lcc}
\hline & n & $(\%)$ \\
\hline Constant Custody & 50 & $(55.6)$ \\
Never Had Custody & 17 & $(18.9)$ \\
Lost Custody & 12 & $(13.3)$ \\
Unstable Custody & 10 & $(11.1)$ \\
Gained Custody & 1 & $(1.1)$ \\
Among Mothers Without Custody (n=40) & & \\
\hline Help to Care for Children not Living with You? & & \\
$\quad$ Consistently Care for Children & 20 & $(50.0)$ \\
$\quad$ Never Care for Children & 10 & $(25.0)$ \\
$\quad$ Occasionally Care for Children & 10 & $(25.0)$ \\
How Often do you See your Child? & & \\
$\quad$ See Children Everyday & & \\
Weekly to Monthly & 4 & $(10.0)$ \\
Almost Never See Children & 28 & $(70.0)$ \\
\hline
\end{tabular}


Table 4

Mental Health at Baseline for Women Who Were Pregnant Over Time $(n=83)$

\begin{tabular}{lcc}
\hline & $\mathbf{n}$ & $(\%)$ \\
\hline Major Depressive Disorder & 27 & $(32.5)$ \\
Conduct Disorder & 54 & $(65.1)$ \\
Post Traumatic Stress Disorder & 43 & $(51.8)$ \\
Drug Abuse & 29 & $(34.9)$ \\
Alcohol Abuse & 34 & $(41.0)$ \\
Alcohol Dependence & 19 & $(22.9)$ \\
\hline
\end{tabular}


Table 5

Mental Health and Motherhood among Women at Final Contact $(n=114)$

\begin{tabular}{|c|c|c|c|c|}
\hline & \multicolumn{2}{|c|}{ Lifetime } & \multicolumn{2}{|c|}{12 Months } \\
\hline & $\mathbf{n}$ & $(\%)$ & $\mathbf{n}$ & $(\%)$ \\
\hline \multicolumn{5}{|l|}{ Have Had Children $(n=68)$} \\
\hline Major Depressive Disorder & 18 & $(26.5)$ & 18 & $(26.5)$ \\
\hline Antisocial Personality Disorder & 45 & $(66.2)$ & 39 & $(57.4)$ \\
\hline Post Traumatic Stress Disorder & 27 & $(39.7)$ & 11 & $(16.2)$ \\
\hline Drug Abuse & 19 & $(27.9)$ & 9 & $(13.2)$ \\
\hline Alcohol Abuse & 16 & $(23.5)$ & 15 & $(22.1)$ \\
\hline Alcohol Dependence & 9 & $(13.2)$ & 9 & $(13.2)$ \\
\hline \multicolumn{5}{|l|}{ Have Custody of Children $(n=36)$} \\
\hline Major Depressive Disorder & 11 & $(30.6)$ & 11 & $(30.6)$ \\
\hline Antisocial Personality Disorder & 21 & $(58.3)$ & 17 & $(47.2)$ \\
\hline Post Traumatic Stress Disorder & 13 & $(36.1)$ & 4 & $(11.1)$ \\
\hline Drug Abuse & 11 & $(30.6)$ & 2 & (5.6) \\
\hline Alcohol Abuse & 7 & $(19.4)$ & 6 & $(16.7)$ \\
\hline Alcohol Dependence & 3 & $(8.3)$ & 3 & $(8.3)$ \\
\hline
\end{tabular}

